\title{
Oxidative Stress, Antioxidant Status and Hs-CRP Levels in Essential Hypertension
}

\author{
Nakkeeran. $\mathbf{M}^{1}$, Periasamy. $S^{2}$, Inmozhi Sivakamisundari. ${ }^{3}$, Ramya. $P^{4}$, \\ Kanagasabai.G ${ }^{5}$ \\ ${ }^{1}$ Department Of Biochemistry, Rajah Muthiah Medical College, Annamalai University,Tamilnadu \\ ${ }^{2}$ Department Of General Medicine, Rajah Muthiah Medical College And Hospital, Annamalai University, \\ Tamilnadu
}

\begin{abstract}
Essential hypertension may lead to severe complication and causes the problems like cardiovascular risk in humans. Increased level of serum cholesterol, TAG, has been observed in patients with hypertension. This study intends to know the levels of oxidative stress, antioxidant status and hsCRP levels in essential hypertensive patients. Totally 160 subjects between 35-55 years age group were included in the study.115 healthy subjects were considered as Essential Hypertension with blood pressure 140/90mmHg and 45 as healthy controls. Patients with secondary hypertension, past history of stroke, coronary artery disease, myocardial infarction, and diabetes mellitus were excluded. Serum lipid profile, total antioxidant status and thiobarbituric acid reactive substances, hsCRP were estimated in these patients by standard procedures and the values were compared with healthy controls. Our study shows that significant increase in TBARS levels and Lipid profile in HTN patients, whereas $H D L-C$, antioxidants, was decreased among hypertensive compared to controls. CRP levels were significantly increased in hypertensive patients when compared to control group. Increasing level of HsCRP leads to cause risk of CVD. Lipid profile, TBARS and CRP levels were significantly raised in HTN patients compare to controls. Thus, monitoring lipid level and maintaining oxidative balance in hypertensive patients would be helpful in preventing the diseases associated with hypertension.
\end{abstract}

Keywords: Hypertension, lipid profile, oxidative stress, total antioxidant status.

\section{Introduction}

Hypertension (HTN), also known as high blood pressure (HBP), is a long term medical condition in which the blood pressure in the arteries is persistently elevated. ${ }^{[1]}$ High blood pressure usually does not cause symptoms. ${ }^{[2]}$ Long term high blood pressure, however, is a major risk factor for coronary artery disease, stroke, heart failure, disease, vision, and chronic kidney disease ${ }^{[3][4]}$ High blood pressure is classified as either primary (essential) high blood pressure or secondary high blood pressure. ${ }^{[5]}$ About $90-95 \%$ of cases are primary, defined as high blood pressure due to nonspecific lifestyle and genetic factors. ${ }^{[5][6]}$ Lifestyle factors that increase the risk include excess salt, excess body weight, smoking, and alcohol. ${ }^{[2][5]}$ The remaining $5-10 \%$ of cases are categorized as secondary high blood pressure, defined as high blood pressure due to an identifiable cause, such as chronic kidney disease, narrowing of the kidney arteries, an endocrine disorder, or the use of birth control pills. ${ }^{[5]}$ Blood pressure is expressed by two measurements, the systolic and diastolic pressures, which are the maximum and minimum pressures, respectively. ${ }^{[2]}$ Normal blood pressure at rest is within the range of 100 140 millimeters mercury $\left(\mathrm{mmHg}\right.$ ) systolic and $60-90 \mathrm{mmHg}$ diastolic. ${ }^{[7]}$ High blood pressure is present if the resting blood pressure is persistently at or above $140 / 90 \mathrm{mmHg}$ for most adults. ${ }^{[5]}$ Different numbers apply to children. ${ }^{[8]}$ Ambulatory blood pressure monitoring over a 24-hour period appears more accurate than office best blood pressure measurement. ${ }^{[1][5]}$ Lifestyle changes and medications can lower blood pressure and decrease the risk of health complications. ${ }^{[9]}$ Lifestyle changes include weight loss, decreased salt intake, physical exercise, and a healthy diet. ${ }^{[5]}$ If lifestyle changes are not sufficient then blood pressure medications are used. ${ }^{[9]}$ Up to three medications can control blood pressure in $90 \%$ of people.${ }^{[5]}$ The treatment of moderately high arterial blood pressure (defined as $>160 / 100 \mathrm{mmHg}$ ) with medications is associated with an improved life expectancy. ${ }^{[10]}$ In the recent studies from India reveals that circulating inflammatory molecules, such as heat sensitive C-reactive protein (hsCRP) and interleukin-6 are increased in hypertensive patients and their levels are predict the onset of hypertension. ${ }^{[1]}$ Oxidative stress can occurs when there is an imbalance between the generation of reactive oxygen species (ROS) and the antioxidant defense systems and it may shows evidence that can induce hypertension. ${ }^{[12]}$ High levels of hsCRP may leads to increase blood pressure by reducing nitric oxide production in endothelial cells. ${ }^{[13]} \mathrm{HsCRP}$ has been measured to found an independent risk factor for the development of hypertension. ${ }^{[14]}$ It plays an efficient marker for inflammation and it is not detected at a very low level $(<3 \mathrm{mg} / \mathrm{l})$ by our routine lab methods. ${ }^{[15]}$ Elevated blood pressure in pre hypertensive stage is considered as a risk factor for increasing cardiovascular diseases. ${ }^{[16]}$ There is an imbalance between oxidative stress and 
antioxidant status is widely seen in hypertensive patients. Hence, these ROS are controlled by wide spectra of enzymatic and non-enzymatic antioxidants. ${ }^{[17]}$ This present study intends to know the role of levels in oxidative stress, antioxidant status and hsCRP in essential hypertension.

\section{Methods And Materials}

This prospective study was carried out in the Department of Biochemistry, Rajah Muthiah Medical College and Hospital, Annamalai University. A volume of $5 \mathrm{ml}$ of fasting venous blood sample was collected in Clot activator tube with aseptic precautions and serum were separated, aliquoted and kept at $-20^{\circ} \mathrm{C}$ for testing. 115 subjects of both male and female age group between $35-55$ years were included in the study as a test group with Essential Hypertension of blood pressure 140/90mmHg and 45 subjects were considered as healthy subjects with normal blood pressure $120 / 80 \mathrm{mmHg}$. Patients with secondary hypertension, past history of stroke, coronary artery disease (CAD), myocardial infarction, and peripheral vascular disease and diabetes mellitus were excluded. Serum lipid profile, plasma total antioxidant status (TAS) and serum thiobarbituric acid reactive substances (STBARS) hsCRP were estimated in these patients by standard procedures and the values were compared with healthy control subjects. Separated serum was used to analyze lipid profile, uric acid, Malondialdehyde (MDA), Total antioxidant status (TAS) and serum thiobarbituric acid reactive substances (STBARS) hsCRP were estimated in these patients by standard procedures and the values were compared with healthy control subjects.Total cholesterol, high density lipoprotein cholesterol (HDL-C), Triglyceride (TG), uric acid was estimated using Erba assay kits. Low density lipoprotein cholesterol (LDL-C) was calculated by Freidewalds formula. ${ }^{[18]}$ Very low density lipoprotein cholesterol (VLDL- C) was calculated by formula TG/5. MDA was measured using thio-barbituric acid (TBA). The mixture was heated at $100 \mathrm{C}$ for $15 \mathrm{~min}$, allowed to cool and centrifuged at 5000rpm. Total anti-oxidant status was assayed by measuring FRAP (ferric reducing activity of plasma). It uses antioxidant as reductant in a redox linked colorimetric method. At lower $\mathrm{pH}$, reduction of a ferric tripyridyltriazine complex to a ferrous form produces an intense blue color, which is measured at $593 \mathrm{~nm}$.Statistical software: Fischer exact test with Yates correction has been used to find out the significance $(\mathrm{p} \leq 0.05)$ for small number of samples for various parameters among cases and controls.

\section{Result}

The compared value of the study groups both hypertension and control subjects are shown in the table 1 . Total cholesterol, TAG, LDL $(\mathrm{P}<0.05)$ were significantly increased in hypertension patients when compared with controls group, whereas HDL-C $(\mathrm{P}<0.05)$ and total antioxidant status of hypertension patient group was significantly decreased among hypertensive compared to controls $(\mathrm{P}<0.05)$ marking ongoing oxidative stress in hypertensive. The level of MDA and hsCRP levels were significantly increased in hypertension patients compared to control group $(\mathrm{P}>0.05)$.

Table/Fig 1: Comparison of study variables in test and controls studied

\begin{tabular}{|l|l|l|l|}
\hline Variables & Test group $\mathbf{N}=\mathbf{1 1 5}$ & Control group $\mathbf{N = 4 5}$ & P value \\
\hline Age in years & $49.33 \pm 10.01$ & $50.71 \pm 10.06$ & 0.499 \\
\hline FBS $(\mathrm{mg} / \mathrm{dl})$ & $91.30 \pm 9.22$ & $86.66 \pm 5.83$ & 0.002 \\
\hline SBP(mmHg) & $158.15 \pm 10.46$ & $121.39 \pm 8.03$ & 0.001 \\
\hline DBP(mmHg) & $102.15 \pm 6.16$ & $81.08 \pm 4.70$ & 0.001 \\
\hline Triglycerides $(\mathrm{mg} / \mathrm{dl})$ & $126.97 \pm 29.29$ & $111.78 \pm 23.91$ & 0.002 \\
\hline Total cholesterol $(\mathrm{mg} / \mathrm{dl})$ & $189.71 \pm 25.99$ & $175.95 \pm 23.42$ & 0.002 \\
\hline HDL $(\mathrm{mg} / \mathrm{dl})$ & $43.73 \pm 2.79$ & $54.34 \pm 4.72$ & 0.004 \\
\hline LDL $(\mathrm{mg} / \mathrm{dl})$ & $89.28 \pm 19.90$ & $81.83 \pm 13.51$ & 0.022 \\
\hline MDA $(\mathrm{mM} / \mathrm{L})$ & $13.36 \pm 1.77$ & $14.06 \pm 1.82$ & 0.026 \\
\hline TAS $(\mathrm{mM} / \mathrm{L})$ & $193.61 \pm 54.72$ & $226.68 \pm 62.78$ & 0.001 \\
\hline hsCRP & $3.86 \pm 1.04$ & $3.42 \pm 0.63$ & 0.008 \\
\hline
\end{tabular}

\section{Discussion:}

Our data clearly show that significant increase in Total Cholesterol, Triglyceride, LDL-C, MDA, CRP, uric acid, whereas HDL-C, antioxidants, were decreased among hypertensive compared to controls, marking ongoing oxidative stress in hypertensive patients. Blood pressure values occur within a continuum, and are determined by mechanical, hormonal and environmental factors. The cardiovascular risks associated with BP depend upon the combination of risk factors in an individual, such as age, gender, weight, physical activity, smoking, family history, serum cholesterol, diabetes mellitus and pre-existing vascular disease. Thus a practical definition of hypertension is 'the level of BP at which the benefits of treatment towards the significance of the costs and hazards ${ }^{[19]}$ According to Kumari et al., concluded in their study that, there is a link between dyslipidemia in hypertensive patients and impaired antioxidant efficiency in essential hypertensive men's. Decrease in FRAP in hypertensive is evident of decreased antioxidant status from $\mathrm{Fe}^{3+}$ to $\mathrm{Fe}^{2+}$. Increase in $\mathrm{Fe}$ and it initiate lipid peroxidation for further it inducing cellular damage. Total cholesterol and LDL-C elevation due to the presence 
of free radicals, the oxidation of LDL-C is increased and leading to coronary disorders in hypertensive. Due to imbalance in counteracting mechanisms to maintain vascular homeostasis, leads to vasoconstriction. These changes are effective in response to enhanced oxidative stress. ${ }^{[20]}$ In our present study, there was significant increase in lipid profile and decrease level in LDL-C. LDL-C is vasoconstrictive, mitogenic, pro-inflammatory and thrombogenic. Hypertriglyceridemic hypertensive is indication of insulin resistance accompanied by modified vascular reactivity as well as elevated catecholamine and adrenocorticotropic hormone. Lipoproteins also strongly contribute to atherogenesis, playing a relevant role in hypertension. ${ }^{[21]}$ An earlier report from India indicates that higher levels of MDA indicates an increased in lipid peroxidation. ${ }^{[22]}$ Oxidative stress because of excessive production of ROS outstripping antioxidant defense mechanism has been implicated in many pathophysiological conditions that affect the cardiovascular system, such as hypercholesterolemia, diabetes, and hypertension. ${ }^{[23,24]}$ Decreased antioxidant capacity and increased ROS release were shown to be associated with essential hypertension. ${ }^{[25]}$

C-reactive protein also increases the cardiovascular risks by several mechanisms. It decreases the production of nitric oxide by endothelial cells, so indirectly it can inhibits vasodilatation. On the other side, it increases leukocyte adhesion, platelet activation, oxidation, thrombosis and also HsCRP can up regulates the angiotensin type-1 receptor so mediates the angiotensin-II mediated increase in blood pressure ${ }^{[26,27]}$ Some of studies refers that high sensitive C- reactive protein (HsCPR) has a role in development of hypertension. According to the Korean population, the researcher found that hsCRP will be an independent risk factor for development of hypertension in Korean population. ${ }^{[28]}$

\section{Conclusion}

Our study shows that significant increase in Total Cholesterol, Triglyceride, LDL-C, MDA, uric acid, whereas HDL-C, antioxidants, was decreased among hypertensive patients when compared to controls, marking ongoing oxidative stress in hypertensive. HsCRP levels were significantly increased in hypertensive patients when compared to control group. Increasing level of high sensitive C - reactive protein may lead to cause risk of Cardio Vascular Disease and atherosclerosis etc.,

\section{References}

[1] Naish, jeannette; court, denise syndercombe (2014). Medical sciences (2 ed.). P. 562. Isbn 9780702052491.

[2] "high blood pressure fact sheet". Cdc. February 19, 2015. Retrieved 6 march2016.

[3] Lackland, dt; weber, ma (may 2015). "Global burden of cardiovascular disease and stroke: hypertension at the core." The canadian journal of cardiology. 31 (5): 569 -71.doi:10.1016/j.cjca.2015.01.009. Pmid 25795106.

[4] Mendis, shanthi; puska, pekka; norrving, bo (2011). Global atlas on cardiovascular disease prevention and control (pdf) (1st ed.). Geneva: world health organization in collaboration with the world heart federation and the world stroke organization. P. 38.ISBN 9789241564373.

[5] Poulter, nr; prabhakaran, d; caulfield, m (22 august 2015). "Hypertension.". Lancet (london, england). 386 (9995): 80112. Doi:10.1016/s0140-6736(14)61468-9. Pmid 25832858.

[6] Carretero oa, oparil s; oparil (january 2000). "Essential hypertension. Part i: definition and etiology". Circulation. 101 (3): 32935. Doi:10.1161/01.cir.101.3.329.Pmid 10645931.

[7] Giuseppe, mancia; fagard, r; narkiewicz, k; redon, j; zanchetti, a; bohm, m; christiaens, t; cifkova, r; de backer, g; dominiczak, a; galderisi, m; grobbee, de; jaarsma, t; kirchhof, p; kjeldsen, se; laurent, s; manolis, aj; nilsson, pm; ruilope, lm; schmieder, re; sirnes, pa; sleight, p; viigimaa, m; waeber, b; zannad, f; redon, j; dominiczak, a; narkiewicz, k; nilsson, pm; et al. (july 2013). "2013 esh/esc guidelines for the management of arterial hypertension: the task force for the management of arterial hypertension of the european society of hypertension (esh) and of the european society of cardiology (esc)". European heart journal. 34 (28): $2159-$ 219.doi:10.1093/eurheartj/eht151. Pmid 23771844.

[8] James, pa.; oparil, s.; carter, bl.; cushman, wc.; dennison-himmelfarb, c.; handler, j.; lackland, dt.; lefevre, ml.; et al. (dec 2013). "2014 evidence-based guideline for the management of high blood pressure in adults: report from the panel members appointed to the eighth joint national committee (jnc 8)". Jama. 311 (5): 507-20. Doi:10.1001/jama.2013.284427. Pmid 24352797.

[9] "how is high blood pressure treated?". National heart, lung, and blood institute. September 10, 2015. Retrieved 6 march 2016.

[10] Musini, vm; tejani, am; bassett, k; wright, jm (7 october 2009). "Pharmacotherapy for hypertension in the elderly." The cochrane database of systematic reviews (4):cd000028. Doi:10.1002/14651858.cd000028.pub2. Pmid 19821263.

[11] Pauletto p, ratazzi $\mathrm{m}$. Inflammation and hypertension: the search for a link. Nephrology dialysis transplantation 2006; 21(4): 850853 .

[12] (becker lb: new concepts in reactive oxygen species and cardiovascular reperfusion physiology. Cardiovascular res 2004; 61: 461470. ( juránek i, bezek s : controversy of free radical hypothesis: reactive oxygen species cause or consequence of tissue injury? Gen physiol biophys 2005; 24: 263-278).

[13] Sesso hd, buring je, rifai n, et al. C-reactive protein and the risk of developing hypertension. Jama 2003; 290: 29452951

[14] Bautista le, lopez- jaramillo, vera lm, casas jp, otero ap, guaracao ai. Is c - reactive protein an independent risk factor for essential hypertension? J hypertens. 2001; 19(5):857-61.

[15] Mendall ma, patel p, ballam 1, strachan d,northfield tc. C-reactive protein and its relation to cardiovascular risk factors: a population based cross-sectional study. Bmj. 1996; 312:1061-5.

[16] King de, egan bm, mainous ag 3rd, geesey me, et al. Elevation of c - reactive protein in people with prehypertension. J clinhypertens 2004; 6: 562-8.

[17] J pedro-botet, mi covas et al. decreased endogenous antioxidant enzymatic status in essential hypertension. Journal of human hypertension2000; 14 : 343-345.

[18] Davidson's principles and practice of medicine $22^{\text {nd }}$ edition: d.e. Newby n.r. Grubb a. Bradbury, cardiovascular disease - vascular disease (hypertension) page no: 607. 
[19] Shantha kumari. N, hemalatha, sheethal. K. C, shwetha, rashmi. T.m. Antioxidant status, oxidative stress and lipid profile in essential hypertensive men journal of evolution of medical and dental sciences/ volume 2/ issue 17/ april 29, 2013 page-2950

[20] Ab bhavani, kb sastry, $\mathrm{n}$ krishna reddy, $\mathrm{t}$ padma . Lipid profile and apolipoprotein e polymorphism in essential hypertension. Indian heart j 2005; 57: 151-157.

[21] Steinberg d, witztum jl. Is the oxidative modification hypothesis relevant to human atherosclerosis? Do the antioxidant trials conducted to date refute the hypothesis? Circulation 2002; 105: 2107-2111.

[22] P subash, p gurumurthy, a sarasabharathi* and $\mathrm{k} \mathrm{m}$ cherian** urinary 8-ohdg: a marker of oxidative stress to dna and total antioxidant status in essential hypertension with south indian population Indian journal of clinical biochemistry, 2010 / 25 (2) 127 132 .

[23] Chisolm gm, steinberg d. The oxidative modification hypothesis of atherogenesis: an overview. Free radic biol med 2000; 28: 1815-1826.

[24] Prabha ps, das un, koratkar r, sagar ps, ramesh g. Free radical generation, lipid peroxidation and essential fatty acids in uncontrolled essential hypertension. Prostaglandins leukot essent fatty acids 1990; 41: 27-33.

[25] Biol Med 2000; 28: 1815-1826. Russo C, Olivieri O, Girelli D, Faccini G, Zenari ML, Lombardi S et al. Anti-oxidant status and lipid peroxidation in patients with essential hypertension.

[26] Devaraj S, Xu DY, Jialal I. C-reactive protein increases plasminogen activator inhibitor-1 expression and activity in human aortic endothelial cells; implications for the metabolic syndrome and atherothrombosis. Circulation. 2003; 107:398-404

[27] Wang CH, Li SH, Weisel RD, Fedak PW, Dumont AS, Szmitko P, et al. C-reactive protein up regulates angiotensin type 1 receptors in vascular smooth muscle. Circulation. 2003; 107:1783-90.

[28] Sung KC, Suh JY, Kim BS, Kang JH, Kim H, LeeMH, et al. High sensitivity C-reactive protein as an independent risk factor for essential hypertension Am J Hypertension. 2003; 16:429-33. 